ISSN: $1130-2887$

\title{
HACIENDO CONSTITUCIONES DEMOCRÁTICAS. EL PROYECTO DE CONSTITUCIÓN DEL CENTENARIO PREPARADO POR LA ASAMBLEA LEGISLATIVA DE LA REPÚBLICA DE PANAMÁ EN 2003 Making democratic constitutions. The Centenary Constitution project prepared by Panama's Legislative Assembly in 2003
}

Salvador SÁNCHEZ GONZÁLEZ

Secretario técnico de Gobierno-Asamblea Legislativa

salvasan@pty.com

BIBLID [1130-2887 (2003) 35, 87-113]

Fecha de recepción: septiembre del 2003

Fecha de aceptación y versión final: noviembre del 2003

RESUMEN: El artículo es un relato de la reciente experiencia de la Asamblea Legislativa de la República de Panamá, en la preparación de una propuesta integral de cambio constitucional para ese país. Se preocupa por describir tanto los detalles del hecho material de la iniciativa, incluyendo el señalamiento de los protagonistas políticos y los especialistas, así como de aquellos que hicieron aportes como parte de las consultas públicas adelantadas desde la Asamblea Legislativa. Sin embargo, parte importante del artículo consiste en explicar los contenidos del proyecto de reforma, contrastándolos con el derecho constitucional vigente actualmente en Panamá, así como con algunos aspectos sobresalientes de otras iniciativas de reforma del pasado reciente en ese país.

Palabras clave: reforma constitucional, Panamá, Asamblea Constituyente, derecho constitucional.

ABSTRACT: The article is the explanation of the recent experience of the Legislative Assembly of the Republic of Panama, which prepared a proposal for the complete change of the constitutional frame of that country. The article offers a complete description of the initiative, including the name of the politicians between its promoters, as well as the staff of specialists and the members of the civil society that introduce their comments during the public consultation of the project. However, an important part of the paper explains the content of the project, contrasting it with the constitutional law of Panama, as well with other salient aspects of other initiatives of reform from other sources and in other periods.

Key words: constitutional reform, Panama, Constitutional Assembly, Constitutional Law. 


\section{HACIENDO CONSTITUCIONES DEMOCRÁTICAS. EL PROYECTO DE CONSTITUCIÓN DEL CENTENARIO PREPARADO POR LA ASAMBLEA LEGISLATIVA DE LA R. DE PANAMÁ}

\section{CONSIDERACIONES PRELIMINARES}

Para reemplazar una Constitución escrita se requieren dos elementos: textos alternativos que expresen una nueva normatividad y un plan de acción para adoptarlos. A continuación, relato los hechos y presento mis opiniones respecto a uno de los esfuerzos encaminados a dar respuesta al primero de estos asuntos, esfuerzo en el que tuve la oportunidad de participar, desde mis responsabilidades como funcionario de la Asamblea Legislativa de la República de Panamá.

Al proyecto de Reforma Integral de la Constitución Política, que tuvo origen en la Asamblea Legislativa, se le ha denominado informalmente el de la «Constitución del Centenario», por coincidir su preparación con la conmemoración de los primeros cien años de la República. Con carácter preliminar abordaré algunos temas que, por referirse a la totalidad del proyecto, requieren tratamiento separado.

El primero de estos asuntos es el de aclarar la posibilidad técnica de realizar cambios integrales mediante los mecanismos de reforma establecidos en la Constitución vigente. En la Constitución Política de la República de Panamá esto se refiere a los dos mecanismos consagrados en su artículo 308, que implican la aprobación de un texto por la Asamblea Legislativa y su sometimiento a referendo popular, por un lado; o la aprobación del texto de reforma por la Asamblea Legislativa y su aprobación posterior por la Asamblea durante el mandato constitucional siguiente.

Tal y como he dejado sentado en otro lugar ${ }^{1}$, el cambio constitucional debe ser entendido como la categoría general que abarca, tanto a los cambios integrales como a los parciales, tanto a los cambios del texto de la Constitución formal como aquellos que ocurren por vías como la mutación constitucional, tanto a los que se realizan por mecanismos preestablecidos como por mecanismos actualmente no contemplados expresamente en la Constitución escrita; tanto los que implican modificar la Constitución vigente en un único artículo como al proceso de reemplazarla por otra enteramente nueva.

En nuestro entorno, donde aún campea la teoría tradicional del poder constituyente, la posibilidad de revisar íntegramente la Constitución a través de los métodos establecidos en su cláusula de reforma, no suele ser bien recibida².

Ciertamente, la teoría clásica sobre la producción de constituciones, originada en los escritos de Sieyés y continuada por Schmitt a principios del siglo XX, señala una separación diametral entre la reforma, entendida siempre como una modificación parcial realizada por las autoridades constituidas facultadas por una cláusula de la Constitución que se reforma; y por la otra, el reemplazo de la Constitución vigente por otra enteramente nueva ${ }^{3}$, realizada por una asamblea popular con poder absoluto y que asume,

1. S. SÁNCHEZ (2002).

2. Excepción notoria de Humberto Ricord, quien reconoce que «si la reforma es suficientemente extensa y profunda» se produce materialmente una Constitución nueva (1991).

3. Que sea posible hacer constituciones «nuevas» es un asunto al que no me dedicaré en esta ocasión, pero que reviste evidente interés. 
directamente o a través de una comisión especial, la marcha cotidiana de los asuntos públicos, hasta que se concluya la labor constituyente y se elijan nuevas autoridades. Ese esquema ideal, sin embargo, no tiene correspondencia con los procesos históricos de creación constitucional. No encaja en él, por poner sólo un ejemplo, la Constitución española de 1978, preparada por las Cortes Generales utilizando el procedimiento de reforma de las Leyes Fundamentales del franquismo.

En cualquier caso, esta versión del nacimiento de las constituciones forma parte de la teoría tradicional del Poder Constituyente, que tan contundentemente rebatió en Panamá el recientemente desaparecido César Quintero ${ }^{4}$, pero que sigue siendo enseñada en las universidades y repetida por los especialistas dentro y fuera del país, por su indudable simplicidad y valor didáctico. La universalidad de su difusión no ha impedido, sin embargo, que se hayan señalado los problemas que confronta como teorías. Sin embargo, el asunto sobre el que hoy escribo es menos sofisticado: basta constatar que son jurídicamente viables las reformas integrales de las constituciones en base a las cláusulas de reforma en ellas incorporadas.

La posibilidad de reformas integrales utilizando los métodos establecidos en la propia Constitución, incluso adquiere carácter normativo expreso, cuando aparece adoptado en la Constitución Federal de Suiza («La Constitución podrá ser reformada en todo momento, total o parcialmente» $)^{6}$ o en la Constitución de la República Argentina ( $\ll$ La Constitución puede reformarse en todo o en cualquiera de sus partes»); caso este último, en el que además la Convención Constituyente es el único método constitucionalizado para efectuar una reforma ${ }^{7}$.

En la historia constitucional panameña hay también antecedentes de la constitucionalización de las asambleas constituyentes como medio de reforma, que no puede ser entendida sino como reforma integral. Así, en la Constitución del Estado Soberano de Panamá de 1863 se estableció, en su artículo 93, que disponía la posibilidad de «reformar» la Constitución mediante una Convención Constituyente popularmente electa, convocada por medio de una ley aprobada por la Asamblea Legislativa. Se trata de un antecedente que tuvo reiteraciones múltiples a lo largo del siglo XIX ${ }^{8}$.

La constatación de esta realidad en el ámbito de lo histórico, normativo y comparado no nos permite, sin embargo, concluir sobre la conveniencia de adoptar una nueva Constitución a través de los métodos incorporados al texto de la vigente o a través de un órgano estatal de excepción. Simplemente, permite observar que es posible, histórica y normativamente, producir una nueva Constitución a través del procedimiento

4. C. Quintero Correa (s/f).

5. Críticas inteligentes y bien fundamentadas pueden encontrarse en I. Отто (1998). También, en J. L. REQUEJO PAGÉs (1998), en especial en lo referente a los límites del poder constituyente originario.

6. Constitución Federal de Suiza, artículo 192.

7. Constitución de la República Argentina de 1853 reformada en 1994, artículo 30.

8. De modo similar se expresa la Constitución de 1865 en su artículo 127; la de 1868 en su artículo 132; la de 1870 en su artículo 133; la de 1873 en su artículo 139; la de 1875 en su artículo 117. 
de reforma consagrado en la Constitución Política vigente, premisa sobre la cual se trabajó al preparar el proyecto.

Otro aspecto de carácter preliminar es el relativo a la extensión del texto constitucional (en este caso, 423 artículos y 31.569 palabras). Tomada cuenta del objetivo del proyecto -servir de base para el debate constituyente- parece más que razonable contar con un texto exhaustivo. Por esa misma razón, en principio, se adoptaron todos los temas de la Constitución Política vigente, aun cuando se reformularon y, paralelamente, se agregaron numerosos temas nuevos. El producto, casi necesariamente, fue un proyecto más voluminoso. Si en el debate constituyente llegara a parecer conveniente excluir de la jerarquía constitucional algún tema o el desarrollo de algún tema, sencillamente se podía sustraer y utilizar el texto extraído como insumo para los desarrollos legislativos de las normas constitucionales. Desde una perspectiva práctica, sigo pensando que era la mejor alternativa y conviene aclarar que aunque se hubiera adoptado en su totalidad, el proyecto no sería de mayor dimensión que las constituciones vigentes de Brasil, Colombia ni Venezuela, por citar sólo algunas de la región; y, en todo caso, sería poco mayor que las de Uruguay, Guatemala o Ecuador.

Debe admitirse, sin embargo, que en nuestra cultura jurídica existe una tendencia marcada hacia los textos constitucionales detallados, por una apreciación positiva de su relativa intangibilidad respecto a los vaivenes de la política parlamentaria'. Uno de los episodios más recientes y emblemáticos de esta conducta fue el establecimiento de un Título constitucional dedicado al Canal de Panamá, en 1994.

Lo de la intangibilidad relativa del texto de nuestra Constitución Política vigente es menester que lo abordemos. Ciertamente, un texto claro y detallado restringe las posibilidades de una acción estatal arbitraria, pero no las impide ni las endereza, cuando el responsable de la guarda de la Constitución se empeña en ignorar la fuerza normativa de su texto o distorsiona el sentido y alcance de sus normas, como ha ocurrido en Panamá con aburridora frecuencia.

Así, las respuestas que otras propuestas han dado al problema de la extensión y del grado de detalle de una Constitución, no son para nada frívolas y resultan de enorme interés. Por ejemplo, el Foro Visión $2020^{10}$ incluye la idea de las «leyes de rango constitucional» ${ }^{11}$, que serían leyes formales aprobadas con mayorías reforzadas. Estas leyes servirían para colocar en un nivel jerárquico subconstitucional materias frecuentemente elevadas a rango constitucional, lo que mantiene la posibilidad de su reforma periódica sin necesidad de tocar la Constitución. En España, un procedimiento análogo (bajo la denominación de leyes «orgánicas») ha sido objeto de

9. Un efecto, el de la intangibilidad del texto de la Constitución, que es producto de los frecuentemente impracticables métodos de reforma adoptados.

10. Foro de concertación política entre la sociedad civil, los partidos políticos y el Estado convocado por el Comité Ecuménico y auspiciado por el Programa de Naciones Unidas para el Desarrollo (PNUD).

11. Propuesta $n^{\circ} 61$ del Foro Visión 2020. En lo relativo a este asunto hay una mención al control de constitucionalidad de estas leyes por la Corte Suprema de Justicia, pero imaginamos que debe tratarse del Tribunal Constitucional, que mencionan en la Propuesta $\mathrm{n}^{\circ} 74$. 
variadas interpretaciones tanto por el Tribunal Constitucional como por la doctrina, por los problemas prácticos que ha implicado su aplicación: la ambigüedad de las materias que sí admiten regulación mediante leyes de rango constitucional; la calificación de ese carácter por los dignatarios parlamentarios antes del trámite legislativo; la incorporación de normas de las descritas como de exclusivo desarrollo mediante leyes orgánicas, junto a otras no-orgánicas en el mismo texto legal; la potencial inconstitucionalidad de las leyes que desborden los límites respectivos; la relación jerárquica entre Constitución y Ley Orgánica y entre Ley Orgánica y Ley Ordinaria, entre otros.

Se ha señalado que el anteproyecto de Constitución Política del Instituto de Estudios Nacionales (IDEN) contempla implícitamente las leyes de rango constitucional, porque en dicho documento se describe (en su artículo 168) la variedad legislativa de «leyes orgánicas ${ }^{12}$. Sin embargo, esa variedad se distingue por los temas que regula y no por una mayoría agravada para su aprobación, pues la que se exige para ella es la misma que el anteproyecto del IDEN exige para un listado prácticamente exhaustivo de temas potencialmente legislables. Tan sólo con carácter residual se contempla la posibilidad de leyes aprobadas con una mayoría relativa. El modelo del IDEN fue incorporado en el proyecto de la Asamblea con algunas diferencias que examinamos en los párrafos siguientes y no lo entendemos como equivalente del (si bien no desarrollado) esquema de «leyes con rango constitucional» del Foro Visión 2020.

La distinción entre leyes ordinarias y orgánicas se introdujo en el derecho constitucional del Panamá independiente de la Constitución de 1946. Quince de los veintiséis temas de posible desarrollo legislativo previstos expresamente en esa Constitución, corresponden a leyes ordinarias. Entre 1972 y 1983 no existió distinción formal entre leyes ordinarias y orgánicas, pero su reintroducción en las reformas de $1983^{13}$ invirtió la relación cuantitativa entre unas y otras. En contraste con la Constitución de 1946, la reforma de 1983 consideró leyes ordinarias, únicamente: la de amnistía política, la declaración de guerra y la expedición del Reglamento de la Asamblea Legislativa; produciendo la paradoja de que las denominadas leyes ordinarias son más que infrecuentes. Basta examinar la total ausencia de leyes declaratorias de guerra o de amnistía desde el final del régimen militar y la persistencia del antiguo Reglamento de la Asamblea Legislativa desde 1984, si bien se le han hecho diversas modificaciones. Tal y como está diseñada, la categoría de «ley ordinaria» en nuestra Constitución vigente es prácticamente inútil.

El proyecto de la Asamblea contempla como leyes formales, las aprobadas por mayoría absoluta de los miembros de la cámara (una categoría que elimina en la práctica las

12. Según el artículo 168 del anteproyecto del IDEN, son orgánicas las leyes que regulan íntegramente los Órganos Superiores del Estado, y sus instituciones y dependencias directas; las que organizan los entes autónomos, semiautónomos, regionales o municipales, así como los servicios públicos, y las que codifican las diferentes ramas del Derecho.

13. Una crítica a la que nos suscribimos plenamente es la que hace el doctor César Quintero, en el Prólogo a la obra de H. Mitchell (1999). 


\section{HACIENDO CONSTITUCIONES DEMOCRÁTICAS. EL PROYECTO DE CONSTITUCIÓN DEL CENTENARIO PREPARADO POR LA ASAMBLEA LEGISLATIVA DE LA R. DE PANAMÁ}

leyes ordinarias) ${ }^{14} \mathrm{y}$ dos categorías especiales de normas: el Reglamento de la Asamblea, que se excluye de la forma de ley (que adquirió impropiamente desde 1956) para reputarse constitucional (prohibiendo la inclusión en él de asuntos ajenos al trámite legislativo, como podrían ser nuevas prerrogativas parlamentarias); y los instrumentos internacionales de derechos humanos mencionados que adquieran jerarquía constitucional por el voto de dos tercios de los miembros de la cámara, tal y como lo señala expresamente el artículo 5 del proyecto.

Conviene también detenerse en los puntos de contacto que tienen estos asuntos con la calidad de nuestra democracia y que, por ser técnicos, reciben poca o ninguna atención. El primero de ellos es que desde que el Reglamento de la Asamblea dejó de ser un acto interno del Parlamento (para ser una ley ordinaria) se producen varias inconsistencias, como la posibilidad de que el Ejecutivo ejerza su iniciativa en materia del régimen interno de la Asamblea y la obligación de contar con su sanción para que entre a regir, sin dejar de lado la posibilidad de objetarlo por inconveniente o inexequible. De todos estos temas, sin embargo, destaco el de la aprobación de la ley del Reglamento a través de una mayoría relativa, con lo que se hace posible aprobar las reglas del debate sin la participación de fracciones parlamentarias enteras, en desmedro de los acuerdos sobre procedimiento que deberían promoverse en cámaras auténticamente democráticas.

Otro de los aspectos relacionados con el funcionamiento de la democracia es, por otro lado, la misma disposición que se observa en los distintos textos propuestos a considerar como mayoría básica, para la aprobación de leyes, la mayoría absoluta. En un país como España, en el que la categoría de leyes orgánicas lleva aparejada no sólo el desarrollo de áreas temáticas específicas ${ }^{15}$ sino una mayoría reforzada, es curioso observar que ese reforzamiento implica la adopción de la mayoría absoluta, en lugar de la mayoría simple que se conserva para las restantes leyes. Esta decisión puede vincularse: a que las Cortes constituyentes aparecieron muy fragmentadas en su integración política y a que el sistema de representación proporcional adoptado presagiaba la persistencia de partidos gobernantes con dificultad para alcanzar, por sí solos, mayorías absolutas. En ese contexto parecía políticamente razonable que la mayoría típica para aprobar legislación fuera la mayoría simple ${ }^{16}$.

La utilidad de las leyes «de rango constitucional», que propone el Foro Visión 2020, depende en gran medida de la confianza que se le tenga al ente al que se responsabiliza por la guarda de la Constitución, por un lado; y significa que importantes asuntos quedarían fuera del debate constituyente y remitido (alguno diría que relegado) al debate legislativo.

14. Aunque hay un párrafo relativo aparentemente a las leyes «ordinarias» en el artículo 239.

15. Desarrollo de los derechos fundamentales y de las libertades públicas, pudiendo extenderse a la regulación de la suspensión de derechos fundamentales y los estados de alarma, excepción y sitio; y las organizadoras de instituciones tales como el Tribunal Constitucional, Tribunal de Cuentas, Consejo de Estado, Poder Judicial, Fuerzas y Cuerpos de Seguridad, régimen electoral general, Defensor del Pueblo, Estatutos de Autonomía de las Comunidades Autónomas, entre otras.

16. J. PemÁn Gavín (1991). 
Esto me lleva a una última reflexión preliminar. También en nuestra cultura constitucional hay una disposición a remitir a la ley el desarrollo de las normas constitucionales que me parece exagerada. Hay algo de eso en el proyecto que describiremos a continuación. El desarrollo legislativo de todas las materias contenidas en una Constitución es algo que debe presumirse: es la función del órgano legislativo. Esto no significa que no tenga consecuencias señalar que una determinada materia constitucional será desarrollada por la ley. Es precisamente esa remisión la que podría crear especiales reservas de desarrollo legislativo; o bien que se pretenda postergar la eficacia de una determinada provisión constitucional hasta que ese desarrollo legislativo no sea promulgado contrario al principio general, que haría exigible toda cláusula de la Constitución tan pronto como ésta entre en vigor. Abstracción hecha de las disposiciones finales y transitorias que suelen referirse a la materia. Así las cosas, las muletillas «...según disponga esta Constitución y la Ley», que con tanta prodigalidad se emplean, pueden tener efectos perniciosos desde el punto de vista jurídico.

\section{DECISIÓN POLÍTICA DE PREPARAR EL PROYECTO}

La Asamblea Legislativa es uno de los tres órganos del Estado con iniciativa expresa para reformar la Constitución Política. Por esa sencilla razón, es frecuente que circulen proyectos y rumores, para el inminente cambio parcial o integral de la Constitución. Sin embargo, cuando en octubre de 2002 el director nacional de Asesoría Técnica Legislativa, Harley James Mitchell, nos solicitó algunos documentos típicos de cualquier investigación sobre el cambio constitucional en Panamá ${ }^{17}$, se hizo evidente que algo relevante se estaba gestando. El entonces reciente y nada apacible cambio de clima en la cámara, que llevó a la Presidencia de la Asamblea al legislador Carlos R. Alvarado A. ${ }^{18}$, permitía presagiar iniciativas arriesgadas y la de la reforma de la Constitución apareció como la más interesante de todas. Sin embargo, sé perfectamente que la iniciativa no puede desvincularse del momento político que se vivía, tanto como desconozco los detalles del proceso interior que llevó a tomar la decisión. Puedo, sin embargo, dar testimonio sobre los eventos en que participé o que observé personalmente.

Inicialmente, el cambio que se proponía no era integral. En un primer momento, antes de la conformación del grupo de tareas para la Constitución del Centenario, se

17. El anteproyecto del IDEN y el proyecto de ILDEA (Instituto Latinoamericano de Estudios Avanzados, organización privada de carácter cultural).

18. Legislador del Partido Revolucionario Democrático. A inicios de 2002, conjuntamente con otros legisladores del PRD, contribuyó con su voto a la ratificación parlamentaria del nombramiento de dos magistrados de la Corte Suprema de Justicia, contrariando la línea de su partido. Apoyado en ese grupo de disidentes y en los votos de la alianza de gobierno, alcanzó la Presidencia de la Asamblea Legislativa para el período anual comprendido entre el 1 de septiembre de 2002 y el 31 de agosto de 2003. 


\section{HACIENDO CONSTITUCIONES DEMOCRÁTICAS. EL PROYECTO DE CONSTITUCIÓN DEL CENTENARIO PREPARADO POR LA ASAMBLEA LEGISLATIVA DE LA R. DE PANAMÁ}

le pidió a la Unidad de Análisis Constitucional de la Asamblea un primer texto, relativo a varios de los asuntos que más destacaban en el debate público sobre la Constitución. Ese primer proyecto de Reformas circuló poco, pero en el debate del mismo con el presidente de la Asamblea Legislativa y sus asesores más cercanos, permitió evidenciar la necesidad, no de cambios parciales, sino de un proyecto de Reforma Integral de la Constitución Política; en la práctica, una nueva Constitución. Para que esto sucediera se preparó un sustento político mínimo, constituido por una Resolución de la Directiva de la Asamblea Legislativa en la que los dos vicepresidentes (recordemos que el primero era Alcibíades Vázquez ${ }^{19}$ y el segundo Alberto Magno Castillero ${ }^{20}$ ), ampliaban significativamente el espacio para impulsar la iniciativa.

El proyecto, en su versión definitiva, se presentaría precisamente a la Directiva de la Asamblea, como mandataria formal del mismo ${ }^{21}$. Aunque se trató de sumar otras voluntades a través de la Directiva ampliada, que integra a los coordinadores de todas las fracciones parlamentarias, mi apreciación es que no fue exitosa.

Desde el inicio, la administración Alvarado sabía que contaba con menos de un año para promover, redactar y aprobar (o no) el proyecto de nueva Constitución. El calendario propuesto exigía agotar el año 2002 en la redacción del texto y el receso parlamentario (enero-febrero de 2002) en la consulta y corrección del texto; para que en la segunda legislatura ${ }^{22}$ ordinaria del período 2002-2003 (marzo-junio de 2003) la Asamblea Legislativa aprobara el texto definitivo una primera vez y lo aprobara nuevamente en la primera legislatura del período anual de sesiones 2003-2004 (septiembre-diciembre). Él culminaría siendo sometido a referéndum popular el día de las elecciones generales en mayo de $2004^{23}$.

En la práctica, se dependía sobre todas las cosas de alcanzar suficientes apoyos políticos para propiciar, por ejemplo, que el proyecto fuera presentado a la Asamblea Legislativa por la presidenta de la República, lo cual aseguraba la probabilidad de su aprobación. Que esos apoyos no llegaron a obtenerse en el plazo y las formas necesarias es ya parte de la historia conocida, sobre la que no hace falta abundar.

19. Legislador del Partido Arnulfista, principal partido en el gobierno panameño durante el período constitucional 1999-2004.

20. Legislador del Partido Solidaridad.

21. Lo que ocurrió el 29 de agosto de 2003 , en un breve acto al que asistieron algunos miembros destacados del Foro Visión 2020 (Néstor Jaén, Jorge Giannareas, Alfredo Castillero). El proyecto se presentó en una edición austera preparada por la imprenta de la Asamblea Legislativa, con la fotografía de los tres miembros de la Directiva impresa en la portada, la presentación del presidente a la Directiva, el listado de colaboradores en la preparación del proyecto y un índice.

22. En Panamá, cada período anual de sesiones consiste en dos «legislaturas» de cuatro meses $\mathrm{y}$ dos recesos de dos meses cada uno.

23. Llamativamente, el texto original del proyecto -y continuó así sin ser corregido a lo largo de todo el proceso- remitía al procedimiento de reforma constitucional contenido en el numeral 1 del artículo 308, que consiste en la aprobación por dos asambleas legislativas consecutivas; y no al numeral 2, que contiene el procedimiento que incluye el referéndum y que era en realidad el programa óptimo y el que se promovió intensamente. 
Hay que recordar que los esfuerzos para adelantar reformas integrales, desde la institucionalidad vigente, han sido sostenidamente obstruidos a lo largo de los años recientes. No pudo concretarse la reforma de 1992; no se aprobó la introducción de un nuevo método de reforma (la Constituyente Paralela) en las reformas de 1994 y no llegó siquiera a presentarse el proyecto de Constitución del Centenario en 2003. La situación ahora está servida para un cambio constitucional integral por procedimientos distintos a los establecidos. Sin embargo, lo relevante para este escrito es reflexionar sobre la experiencia concreta del proyecto de la Asamblea.

Cuando la Asamblea Legislativa ofreció una alternativa para el reemplazo de la Constitución Política por mecanismos constitucionales, a finales de 2002, ni la mayoría de los políticos partidarios ni los activistas de la sociedad civil, estaban listos para tomar en serio la oportunidad que se brindaba. No puede especularse sobre las razones de esa falta de disposición, pero en el caso de los políticos partidistas, era más que un nuevo episodio de su proverbial resistencia a los cambios profundos a nuestro ordenamiento constitucional. Las cicatrices de la rebelión legislativa dentro del PRD, en septiembre de 2002, y los temores que despertaba en gobierno y oposición la nueva administración de la Asamblea Legislativa, pueden señalarse como ingredientes que jugaron en contra de la credibilidad del proyecto.

La desconfianza de algunos activistas de la sociedad civil fue algo distinto, aunque pudo ser previsible. Existían temores por el origen legislativo del proyecto e insatisfacción con el desempeño de la cámara y de sus miembros y, en especial, por los últimos y graves escándalos ${ }^{24}$.

Por otro lado, la actitud general ante las ofertas de cambio constitucional, basadas en los métodos de reforma establecidos en la Constitución vigente, también implicaron resistencia al proyecto presentado por la Asamblea Legislativa, aunque a principios de 2003 era lo menos importante. Probablemente haya incidido, con mayor intensidad, la propia fragmentación, diversidad y conflictos de la sociedad civil, cuyo escenario de articulación más ambicioso hasta el momento (el Foro Visión 2020), es paradójicamente un escenario de diálogo con los partidos políticos y el Estado.

Así las cosas, la frialdad con la cual fue recibida la iniciativa de la Asamblea Legislativa tuvo, sin embargo, el inesperado impacto de dar contenido a la reiterada conclusión general de que era necesaria una nueva Constitución. Su efecto más dramático

24. El más grave de los cuales es conocido como caso CEMIS (Centro Multimodal, Industrial y de Servicios), que consistió en las denuncias de que la aprobación por la Asamblea Legislativa del Contrato Ley entre el Estado y el Consorcio San Lorenzo para la creación del CEMIS (diciembre de 2001), había incluido el soborno de legisladores de gobierno. La posterior ratificación del nombramiento de dos magistrados de la Corte Suprema de Justicia (9 de enero de 2002) se había alcanzado igualmente con el soborno de legisladores de la oposición política. El escándalo se desató cuando el legislador del Partido Revolucionario Democrático (oposición), Carlos Afú, expuso en conferencia de prensa ( 16 de enero de 2002) la suma de seis mil dólares que había recibido como adelanto del soborno por votar a favor del Contrato Ley del CEMIS, involucrando a legisladores de oposición y gobierno en la misma conducta. 
SALVADOR SÁNCHEZ GONZÁLEZ

96 HACIENDO CONSTITUCIONES DEMOCRÁTICAS. EL PROYECTO DE CONSTITUCIÓN DEL CENTENARIO PREPARADO POR LA ASAMBLEA LEGISLATIVA DE LA R. DE PANAMÁ

aparece precisamente cuando, semanas después, el Foro Visión 2020 hace públicas sus conclusiones en materia constitucional.

\section{REDACCIÓN DEL PROYECTO}

Se estableció un grupo de tareas integrado por varios de los asesores del presidente de la Asamblea Legislativa (en torno a la figura de Mitchell Doens) y un grupo de asesores institucionales de la Asamblea (en torno a la figura de Harley James Mitchell). En conjunto, se denominó a aquello: «Unidad Técnica para la Modernización del Estado Panameño y la Constitución Política de la República», lo que no dejaba de ser un nombre grandilocuente para lo que era sencillamente una fuerza de tareas, con el objetivo único de preparar un proyecto de Constitución Política.

El proceso de redacción se inició sobre la base de la acumulación de información recogida durante varios años, de actividades en materia constitucional organizadas por la Asamblea Legislativa. En esos años habían pasado por el Salón Azul del Palacio Justo Arosemena constitucionalistas como Miguel Antonio Bernal, Humberto Ricord, Edgardo Molino Mola, Carlos Bolívar Pedreschi; y juristas de la talla de Carlos López Guevara, Guillermo Endara25 (el presidente del Colegio Nacional de Abogados), Carlos Vásquez Reyes, entre muchos otros, que dejaron claramente señalado el camino que debería seguir la reforma de las instituciones políticas y jurídicas de la Constitución. También se hizo un examen de los fallidos proyectos de reforma constitucional de 1992, 1994 (recordemos que no se aprobó uno de los tres Actos Legislativos) y de 1998, así como de otras contribuciones hechas a través de los medios de comunicación (principalmente artículos periodísticos), sin excluir las propuestas de reforma integral hasta entonces disponibles: la del Instituto de Estudios Nacionales de la Universidad de Panamá (IDEN) y del Instituto Latinoamericano de Estudios Avanzados (ILDEA). Esa primera tarea quedó en manos principalmente del licenciado Roberto García Flores y su producto fue un largo y exhaustivo listado de propuestas útiles. Sin embargo, debieron eliminarse las propuestas repetidas y se debió optar igualmente entre una de las varias alternativas que se ofrecían para idénticos problemas. Ése fue el punto de partida de la redacción del primer borrador de la nueva Constitución Política.

El trabajo de redacción se ejecutó principalmente en la Secretaría Técnica de Gobierno, Derechos Humanos y Asuntos Indígenas de la Asamblea Legislativa. Como ya es conocido, los servicios técnicos de la cámara incluyen ocho secretarías técnicas, que brindan apoyo multidisciplinario a las 21 comisiones permanentes del Parlamento. La Secretaría Técnica de Gobierno apoya a cuatro comisiones permanentes, incluyendo la Comisión de Gobierno, Justicia y Asuntos Constitucionales. También es la sede de la Unidad de Análisis Constitucional, un ente ad hoc para el tratamiento de asuntos constitucionales de interés para la Asamblea Legislativa. Entre sus especialistas más

25. Presidente de la República entre 1989 y 1994. Fundador del Partido Arnulfista y actualmente candidato presidencial por el Partido Solidaridad. 
destacados se incluyen a Agapito González Gómez, Boris Barrios González y Hernando Franco Muñoz. Así las cosas, era el lugar idóneo para preparar el proyecto de Constitución del Centenario. De hecho, la redacción original de la Exposición de Motivos fue responsabilidad casi exclusiva de Agapito González, que se sirvió de algunos documentos ofrecidos por los asesores presidenciales y de su análisis del texto del proyecto para proporcionarnos una Exposición eficaz. Después, la Exposición de Motivos debió ser adaptada para que reflejara los sucesivos cambios que sufrió el texto antes de su publicación definitiva, pero fueron ajustes menores.

$\mathrm{El}$ articulado se fue integrando poco a poco en la Secretaría Técnica de Gobierno, durante escasas tres semanas de trabajo intensivo. El listado original de propuestas se enriqueció con la influencia de los textos constitucionales aprobados recientemente en Argentina, Colombia, Ecuador y Venezuela, entre otros.

Se trabajó originalmente sobre una tabla de dos columnas que permitía ir proponiendo alternativas de diseño a nuestras instituciones tradicionales, adición de instituciones actualmente inexistentes o reguladas sólo a nivel legal y de regulación en general. Este procedimiento permitía contemplar de forma gráfica cómo y cuánto nos íbamos distanciando de la Constitución vigente. Esos textos se fueron discutiendo en reuniones periódicas en el despacho del asesor presidencial Mitchell Doens y en las que participan regularmente el propio Doens, Harley James Mitchell, Humberto Toala, Roberto García Flores, Pedro Pereira y otros funcionarios, entre los que me hallaba.

Un primer texto completo se colocó en la página web de la Asamblea Legislativa ${ }^{26}$ y se distribuyó entre distintos sectores en enero de 2003, al tiempo que se iniciaban consultas cara a cara con los representantes de distintas organizaciones, los cuales proporcionaron sus ideas por escrito y verbalmente, para que fueran consideradas por los asesores de la Asamblea y, en su caso, incluidas en el proyecto. Algunas consultas se hicieron al más alto nivel, con representantes de la Iglesia Católica, de la dirigencia de los partidos políticos y con los responsables de las universidades del país. También se consultó al Colegio Nacional de Abogados, al Sindicato de Periodistas, al Sindicato de Industriales y a líderes sindicales, entre otros.

Pueden destacarse las reuniones que se realizaron con los representantes del Grupo Dinamizador del Foro Visión 2020 (en una primera ocasión, Raúl Leis y Néstor Jaén, acompañados por Jorge Giannareas), que sirvieron para coordinar la presentación del proyecto ante la Mesa Nueva Constitución del mencionado Foro, explicar los aportes del mismo y atender las recomendaciones de sus miembros.

Que las consultas fueron provechosas y que impactaron en el texto definitivo de la propuesta de la Asamblea, no hay duda. Pueden destacarse dos, relacionadas con el Preámbulo y con el Título del Canal de Panamá; aunque denotaron, más que opciones técnicas, sensibilidad por los intereses de determinados sectores sociales. Tal es el caso de la invocación expresa a Dios en el preámbulo constitucional. Lo que es constitucionalmente relevante, sin embargo, es la separación entre Iglesia y Estado y, en el caso panameño, incluso los fieles católicos pueden discrepar del uso de recursos del

26. http: www.asamblea.gob.pa. 
Estado para sostener el culto católico o para reproducirlo, como ocurre con la constitucionalizada enseñanza del catolicismo en los establecimientos oficiales de educación. El problema de fondo más visible es el trato diferente que reciben las diversas formas de religión organizada. Por otro lado, el tratamiento excepcional de la Iglesia Católica en materia tributaria, migratoria o judicial, por poner algunos ejemplos, depende precisamente de esa vinculación con el texto de la Constitución Política para fundamentarse jurídicamente ${ }^{27}$. En conclusión, el asunto es relevante desde el punto de vista constitucional, aun y cuando se crea en Dios o se practique el culto católico romano.

También fue necesario atender la preocupación de los administradores y trabajadores de la Autoridad del Canal (ACP), por conservar íntegramente las disposiciones constitucionales referentes al Canal de Panamá. En realidad, el Título del Canal que forma parte de la Constitución vigente no puede ser comprendido sino como una mala decisión tomada con intenciones válidas. Por supuesto, los objetivos de no convertir al Canal en un botín de los partidos políticos, de garantizar la estabilidad de las normas que lo rigen y el funcionamiento ininterrumpido de la vía, así como de mantener la credibilidad internacional en la capacidad de los panameños para administrar el Canal se han alcanzado; pero por unos medios que no eran, desde mi perspectiva, los únicos posibles y, ciertamente, no los constitucionalmente razonables. Como consecuencia del Título del Canal, no se ha evitado que el Canal sea un botín (aunque no de los partidos) y que la ACP cotidianamente usurpe las competencias de otros órganos constitucionales y legales, distorsionando el proceso político democrático, con una especie de despotismo ilustrado que le empuja a suscribir acuerdos internacionales y a desarraigar a los campesinos de la cuenca hidrográfica del oeste del Canal contando, eso sí, con recursos ilimitados dedicados a la autopromoción mediática; mientras exhibe una total opacidad a la fiscalización ciudadana. Así las cosas, no puede sorprender que los vínculos internacionales de la ACP con el capital global, le hagan promover activamente el tránsito de material radiactivo peligroso por las aguas de la República de Panamá o que intervenga como competidor privilegiado en el mercado de la electricidad, mientras se define públicamente como «empresa».

Esta conducta la fundamentan en el texto o en la antojadiza interpretación que hacen del texto del Título del Canal y sus correctivos jurídicos deben ser abordados en una próxima reforma constitucional. Resulta realmente una oportunidad perdida la final exclusión de la materia del proyecto de la Asamblea Legislativa, que remite casi literalmente el texto actualmente vigente, si bien la reflexión que motivó es ya un avance.

27. Lo que se hace evidente en fallos como el de 5 de septiembre de 1997 en el que la Corte Suprema de Justicia concluye que nuestra Constitución «pone en evidencia un "cristianismo confeso" del constituyente». 


\section{AsPectos RELEVANTES DEL PROYECTO DE CONSTITUCIÓN DE la Asamblea LegisLativa DE la RepúblicA}

En cuanto al procedimiento de preparación del proyecto, no se confeccionaron actas de las discusiones, como ocurrió también en el caso del anteproyecto del IDEN, aunque reconozco que los debates en la Asamblea fueron breves y poco argumentativos, como correspondía a un esfuerzo signado por plazos agobiantes. Hubiese sido preferible contar también con grupos de especialistas, que analizaran cuestiones particulares para tomar decisiones mejor fundadas. La inexistencia de esos equipos, ausentes también en la elaboración de otros proyectos, no se explicaba en el nuestro, pues la Asamblea Legislativa tenía y tiene recursos humanos suficientes para conformarlos. En cuanto a la forma del proyecto mismo, debo decir que no estoy satisfecho con el estilo, que por momentos resulta desigual y poco elegante, precisamente porque no pudo ser suficientemente trabajado ${ }^{28}$.

Entre los temas propuestos y acremente discutidos, también se encontraba la incorporación del presidente o presidenta de la República, terminado su mandato, a la Asamblea Legislativa. Como debimos aclarar, el ofrecer inmunidad parlamentaria a la actual presidenta de la República, que señalaban algunos como justificación de esta propuesta, no tenía ningún asidero, dada la extensión, vía el Tratado del PARLACEN, a todo ex presidente, del carácter de parlamentario centroamericano. Como se sabe, corresponde a los parlamentarios centroamericanos la inmunidad que tienen los legisladores en su país de origen. No era, por tanto, necesario ofrecer una inmunidad a la presidenta de la República, que de todas formas va a tener. Muy por el contrario, el mecanismo proporcionaba una alternativa para incorporar a la Asamblea Legislativa a personas que por haber ocupado la más alta magistratura de la República, conocen o deben conocer el funcionamiento del Estado, sus capacidades reales y sus compromisos nacionales e internacionales. De esa forma, si bien en teoría, podría enriquecerse el debate parlamentario. Ahora bien, la notoria antipatía que despertó esta disposición, aunque sin fundamentos de peso, hubiera justificado por sí sola su remoción del proyecto.

\section{El Estado y la Nación}

En lo relevante a la caracterización del Estado panameño, el proyecto le definía como Estado social y participativo. Una de las novedades radica, tan sólo, en la explicitud del carácter «social» del Estado, pues los contenidos de la Constitución Política vigente ya permiten definirlo como tal, al menos nominalmente (pues no son eficaces muchas de las normas que al respecto integran la Constitución). Una fórmula política parecida

28. Debe reconocerse, sin embargo, el apoyo de la Secretaría Técnica de Redacción y Corrección de Estilo, a cargo de la licenciada Marta Espino, que garantizó la ausencia de errores sintácticos y ortográficos. 
se adoptó en el proyecto del IDEN, en 1994, al declarar al Estado panameño como «Estado social de Derecho». Más precisa y elegante sería la fórmula que declara a nuestro Estado como «social y democrático de Derecho». Lamentablemente, se había edificado sobre el artículo 1 del texto vigente; con lo cual, la introducción únicamente del adjetivo «social» (y no también «democrático») permitía evitar un conflicto con la parte final del artículo, que se refería a la forma de gobierno como democrática y representativa. Por supuesto, como lo captó correctamente Miguel Antonio Bernal, el problema radicaba en no haber sido suficientemente osados en ese primer Título. Debimos haber construido un artículo 1 íntegramente nuevo y, adelanto, estaban en el tintero otras propuestas que caracterizaban al Estado como multiétnico y pluricultural; que de haberse introducido, encajarían a la perfección con el desarrollo que en el articulado se le dio al tema de la autonomía indígena en el marco del Estado.

La otra novedad aparente del artículo 1 radica en la introducción del carácter «participativo» de la forma de gobierno, que tiene una concreta repercusión en la incorporación al proyecto de las postulaciones libres a todos los cargos de elección popular; la iniciativa popular para aprobar y derogar legislación; la revocatoria popular de la mayoría de los mandatos electorales; el establecimiento de la iniciativa popular para la reforma de la Constitución, entre otros mecanismos. Debe advertirse, sin embargo, que desde el proyecto de ILDEA de 1993, ese tipo de instrumentos para promocionar la participación ciudadana ya no son novedosos en sí mismos.

A pesar de esos antecedentes, el concepto «democracia participativa» no fue siempre bien recibido, aunque la mayoría de las veces estimamos que se debía a que no era bien entendido. En ocasiones, la democracia participativa se consideraba simplemente una influencia reciente de la Constitución de la República Bolivariana de Venezuela, que se identificaba a su vez con el régimen de Hugo Chávez, a quien se le atribuían y atribuyen enormes arbitrariedades. Sin embargo, la idea de promover la participación de los ciudadanos en los asuntos públicos es, como sabemos, muy anterior a la Constitución venezolana y, en cualquier caso, dista mucho de tender a la arbitrariedad de los gobernantes. Por el contrario, su premisa es la profundización de la democracia que, en regímenes exclusivamente representativos, suspende la relevancia del ciudadano entre un torneo electoral y otro. Sin embargo, es cierto que la Constitución de la República Bolivariana de Venezuela ofrece una variedad de instituciones, muchas de ellas de talante participativo, que sirvieron de referencia durante la redacción del proyecto de la Asamblea Legislativa. Pero el carácter participativo de esas instituciones poco tiene que ver con la conducta del presidente venezolano.

Otra cosa es atacar, por razones ideológicas o de interés personal, la intervención del Estado en la economía. Esa intervención es autorizada por la Constitución vigente e incluso es obligada en determinadas actividades (si bien las políticas económicas neoliberales, avaladas por la Corte Suprema de Justicia, han dotado de ineficacia a varias de las disposiciones en que quedaba consagrada). En este punto, es notable la distancia entre los proyectos del ILDEA y de APEDE (Asociación Panameña de Ejecutivos de Empresa), que valoran negativamente la intervención del Estado y la Asamblea Legislativa en la economía. El proyecto de la Asamblea Legislativa autoriza la intervención 
SALVADOR SÁNCHEZ GONZÁLEZ

HACIENDO CONSTITUCIONES DEMOCRÁTICAS. EL PROYECTO DE CONSTITUCIÓN DEL

CENTENARIO PREPARADO POR LA ASAMBLEA LEGISLATIVA DE LA R. DE PANAMÁ

del Estado, si bien no hace obligatoria esa intervención, con lo que queda preservada, tanto la propiedad privada y la iniciativa empresarial como el deber del Estado de regular las relaciones entre los ciudadanos para evitar la comisión de abusos y la equidad social.

Igualmente, fue enfático en la introducción de la declaratoria de neutralidad del territorio de la República y en la prohibición de presencia de tropas extranjeras en suelo patrio. En principio, son todas propuestas cuya conveniencia subscribo plenamente.

Resulta interesante señalar, sin embargo, que sobre el asunto de la neutralidad, Miguel Antonio Bernal propuso que se extendiera, más allá del territorio, a la conducta del Estado en el concierto de la comunidad de naciones. También sobre la prohibición de tropas extranjeras, Francisco Linares advirtió que el precepto podría entenderse como abarcador de los agentes extranjeros responsables de la capacitación de nuestros policías o de los esfuerzos conjuntos que realizaba Panamá con Estados amigos para combatir el terrorismo o el narcotráfico. Ciertamente, estos puntos son atendibles y, de haberse propiciado el debate constituyente en la Asamblea Legislativa, hubieran debido ser planteados. Con lo que definitivamente no podemos estar de acuerdo es con preceptos como el del artículo 4 del proyecto de ILDEA, que se refieren a la «intrascendencia de las fronteras nacionales para lograr el respeto y plena vigencia» de los derechos humanos ${ }^{29}$. Las fronteras nacionales sí son relevantes, aun y cuando participe del criterio de que los derechos humanos son universalmente reconocidos y de que deben ser universalmente respetados. La tensión entre la autodeterminación de los pueblos, la prohibición de las guerras de agresión y la obligación de la comunidad internacional para intervenir en uno de sus integrantes cuando se practiquen graves, masivas y sistemáticas violaciones a los derechos humanos, es enorme, como nos lo demuestra la historia reciente, pero en ningún caso conduce a considerar intrascendentes las fronteras nacionales.

\section{DERECHOS FUnDAMENTALES}

En materia de derechos fundamentales intentamos seguir a grandes rasgos la organización de la materia realizada por el IDEN en su proyecto. No fue sencillo, porque simultáneamente nos propusimos enriquecer el catálogo de derechos fundamentales, con lo cual se abrió la posibilidad de duplicar algunas disposiciones y de omitir otras. Así, en una de las presentaciones ante la Mesa Nueva Constitución del Foro 2020 se hicieron dos observaciones valiosas que sirvieron para mejorar aspectos fundamentales, como la regulación de la inviolabilidad del domicilio y de la libertad de expresión ${ }^{30}$.

29. Artículo 4 del proyecto de nueva Constitución del Instituto Latinoamericano de Estudios Avanzados.

30. Éstas fueron hechas por el licenciado Saúl Maloul, entonces representante en la Mesa Nueva Constitución de Transparencia Internacional ante el Foro 2020. 
De las contribuciones del proyecto a la materia de los derechos fundamentales destacan la reformulación del amparo y del hábeas corpus, a la par de la adición, a nivel constitucional, del hábeas data. En lo relativo al amparo, se corrige su denominación (para ser amparo de derechos constitucionales) y podrá ser interpuesto contra acciones u omisiones de autoridades o particulares (en lugar de contra órdenes de hacer o no hacer emitidas por autoridad).

Mientras que con respecto al hábeas corpus se diseña de forma tal, que lo atacado pueda ser tanto la detención como la orden de detención, resolviéndose el asunto constitucional de los hábeas corpus preventivos.

Entre los derechos por primera vez constitucionalizados, están el derecho a la intimidad, a la tutela judicial efectiva; el derecho a asistencia legal desde el momento de ser llamado a declarar (en lugar de desde el momento de su detención); la eliminación de la obediencia debida como eximente de responsabilidad penal; la introducción de programas de educación para los detenidos preventivamente; normas para hacer aplicable el Estatuto de Roma sobre la Corte Penal Internacional; la inviolabilidad de las comunicaciones en un sentido que impida una interpretación judicial como la vigente (que autoriza ciertos excesos); derecho a la información; derecho de petición ante los organismos internacionales.

Como parte de las garantías relativas al estado de excepción, se aclaran los derechos que pueden ser suspendidos de conformidad con el derecho internacional que regula la materia, y se establecen los mecanismos para poder impugnar la suspensión de derechos cuando no se ajuste a los requisitos constitucionales.

El asunto de los derechos sociales también es abordado, si bien las diferencias con la regulación actual de la materia (que es bastante completa), no son tan grandes. Destaca, sin embargo, la introducción de un capítulo especial sobre los derechos de los discapacitados y el desarrollo de los derechos de los ancianos, los niños y adolescentes; así como ciertas garantías sobre el estatuto de los extranjeros, como grupos especialmente vulnerables.

Quizá destaque más la renovación de la justicia laboral, donde se enfatiza el papel técnico de la decisión a nivel de las Juntas de Conciliación y su revisión por autoridades judiciales. La Sala de lo Social de la Corte Suprema de Justicia, que aparece establecida en la parte orgánica de la administración de justicia, según el proyecto, cerraría el sistema.

También una importante simplificación al régimen de las uniones de hecho, que admite interpretaciones muy progresistas, así como la elevación de la Caja del Seguro Social a entidad constitucionalizada.

En materia educativa debe resaltarse la clarificación del papel del Estado en la promoción y la supervisión de la enseñanza oficial y particular, así como la capacidad de establecer mediante ley un número plural de instituciones de enseñanza superior, cuya autonomía estaría garantizada por la dotación original de un patrimonio y su administración independiente. Un nuevo ente, el Consejo Nacional para la Educación Superior, supervisaría el funcionamiento de las universidades, oficiales o particulares. 
SALVADOR SÁNCHEZ GONZÁLEZ

HACIENDO CONSTITUCIONES DEMOCRÁTICAS. EL PROYECTO DE CONSTITUCIÓN DEL

CENTENARIO PREPARADO POR LA ASAMBLEA LEGISLATIVA DE LA R. DE PANAMÁ

También se regulan los temas ambientales y bioéticos, en extremos llamativos, como aquel que prohíbe el paso de desechos tóxicos por el territorio nacional, el patentar el genoma humano o la clonación de humanos.

Un último apartado, relativo a los pueblos indígenas, visibiliza el papel constitutivo de este segmento de la población en la integración del Estado, asegurando los derechos que tradicionalmente les ha reconocido el más reciente constitucionalismo panameño y fijando otros parámetros que se corresponden con el desarrollo legislativo e internacional en la materia.

No menos importante es la obligación del Estado de velar por la defensa y difusión de los idiomas de los pueblos indígenas, disposición que en la Constitución vigente existe únicamente respecto del español.

Por otro lado, el reconocimiento de la autonomía administrativa en la forma de Comarcas, que tiene después desarrollo en el apartado sobre régimen territorial y en lo relativo al régimen electoral, es indudablemente una innovación que valoramos enormemente.

En este último aspecto es impresionante constatar que gran parte de los conflictos que día a día se van haciendo más frecuentes, generalizados y graves, relacionados con los pueblos indígenas, se deben a la desordenada regulación de esta materia y a la falta de un proyecto claro del Estado multiétnico que somos y a la necesidad de diseñar un entorno más claro, desde el punto de vista jurídico y administrativo.

\section{INSTITUCIONES DE FISCALIZACIÓN}

Entre las instituciones de fiscalización que se elevan por primera vez a la Constitución está la Defensoría del Pueblo. Básicamente aquí se reproduce la experiencia que sobre la regulación constitucional de la entidad se pudo adquirir de la primera propuesta en ese sentido, ofrecida por la Comisión Presidencial para la Defensoría del Pueblo en 1996, que corresponde también, en cierta medida, a la ley aprobada en 1997 y mediante la cual surgió a la vida jurídica la institución. Los únicos e importantes datos que merecen resaltarse son: primero, la elección por 2/3 de los miembros de la cámara (en lugar de mayoría absoluta, como lo establece la ley actual); y segundo, la opción por la designación de los adjuntos del Defensor o Defensora del Pueblo por el titular, pero la necesidad de que éstos sean ratificados por la Asamblea Legislativa.

También se encuentran en esta sección novedades, como la prohibición del control previo por parte del contralor general de la República y la adopción de un Tribunal de Cuentas para fiscalizar el uso de las partidas presupuestarias. Este último, es una figura que de alguna forma ya aparecía en la Ley Orgánica de la Contraloría y que, de forma exitosa, controla los abusos en la Administración Pública en otros Estados. Su adopción, conjuntamente con las reformas a la Contraloría General de la República, permitiría la agilidad en la ejecución de las partidas presupuestarias, adecuadamente previstas en el Presupuesto General del Estado y la exigencia de responsabilidad en caso de abusos (incluyendo la recuperación del patrimonio del 
Estado), sin dejar de establecer las mínimas garantías procesales que todo imputado debe tener.

Una institución nueva, que consideramos fundamental, es también el Tribunal Constitucional, el cual concentraría las funciones del control objetivo de constitucionalidad y participaría de manera central en el control subjetivo de constitucionalidad ${ }^{31}$. Sin embargo, me parece uno de los mayores desatinos del proyecto el establecer el número de tres magistrados para integrar el Tribunal Constitucional. La calidad de nuestra justicia constitucional actual, con todos sus males, se beneficia de la existencia de nueve magistrados, lo que debe suponer una mayor ilustración de los casos y decisiones tomadas, como extremo, sobre la base de una relación de cinco a cuatro. Al contrario, un Tribunal integrado por tres magistrados coloca sobre los hombros de demasiados pocos, la determinación de un conjunto enorme de causas que estimamos de gran importancia. Debe explicarse, sin embargo, que ante la adopción de tantas instituciones nuevas por el proyecto, se externalizó una posición cautelosa por los evidentes costos relacionados, en este caso, a la designación de nuevos magistrados. La conclusión de ese debate, consagrado en el texto del proyecto, fue un Tribunal integrado tan sólo por tres magistrados, con la expectativa que, durante el debate constituyente, pudiera fundamentarse apropiadamente la necesidad de un Tribunal integrado por un número mayor de magistrados.

En términos generales, sin embargo, parece estar mejor diseñado el control de la constitucionalidad en el proyecto de la Asamblea, que en el proyecto de ILDEA; el cual optó por una Sala Constitucional al uso de Costa Rica e introduce formas de selección de los magistrados que no son las típicas ofrecidas por la doctrina ${ }^{32}$.

La ubicación del Tribunal Constitucional entre las instituciones fiscalizadoras, contrario a lo que suponen algunos juristas que propugnan su ubicación en el título correspondiente a la Administración de Justicia, responde a la doctrina, que puede o no ser atendida, que reconoce en el control de constitucionalidad una labor que trasciende lo meramente judicial para convertirse en una defensa del orden constitucional democrático y de los derechos fundamentales, frente a los poderes establecidos. Se espera, por lo tanto, que el órgano judicial actúe únicamente como administrador de justicia, lo cual facilita paralelamente la consolidación de una carrera de méritos en la judicatura y contribuye a aislarla de intervenciones indebidas de los poderes fácticos.

31. Amparo de derechos constitucionales, hábeas corpus, bábeas data, que se atienden según la jerarquía de la autoridad que realiza los actos impugnables por violar la Constitución y corresponderían al Tribunal Constitucional por vía de apelación o cuando los actos procedan de autoridades nacionales.

32. Sobre las opciones que se abren para Panamá, en lo relativo a los mecanismos de control de la constitucionalidad, puede verse M. GONZÁLEZ MARCOS (2003). 
SALVADOR SÁNCHEZ GONZÁLEZ

HACIENDO CONSTITUCIONES DEMOCRÁTICAS. EL PROYECTO DE CONSTITUCIÓN DEL

CENTENARIO PREPARADO POR LA ASAMBLEA LEGISLATIVA DE LA R. DE PANAMÁ

\section{DERECHOS POLÍTICOS}

En este apartado hay múltiples aspectos destacables, pero resalto la ampliación sistemática de todos los espacios de participación de los ciudadanos en la política: ausencia de un monopolio de los partidos políticos para la presentación de candidatos a puestos de elección popular; disminución de los requisitos para formar partidos políticos; revocatoria popular de los mandatos (a excepción de los del presidente y vicepresidentes); garantía del financiamiento público tanto a los partidos como a las campañas electorales (lo que lo extiende a los candidatos libres); consultas populares vinculantes y no vinculantes; iniciativa legislativa y constitucional de los ciudadanos (incluyendo la posibilidad de referéndum derogatorio de la legislación); entre otras.

En lo que respecta a la revocatoria popular del presidente (fenómeno en el que actualmente está inmersa Venezuela), puede verse en el proyecto de la Asamblea una excepción al principio general que autoriza su utilización frente a todas las otras autoridades de elección popular. El proyecto no es coherente en este extremo, pero la excepción implica una concesión a la opinión de que la consagración de la revocatoria popular del presidente implicara una puerta permanentemente abierta a la desestabilización gubernamental. Sin embargo, creemos que el uso perverso de este mecanismo democrático depende en no poca medida de su adecuada regulación, y podría ser reconsiderada.

Por otro lado, puede observarse en el proyecto de la Asamblea la adopción generalizada del principio de la libre postulación ${ }^{33}$. Personalmente no favorezco la libre postulación para integrar la Asamblea o para elegir al presidente de la República. Me parece un instrumento que de introducirse perjudicará irremediablemente la gobernabilidad democrática, promoverá aún más el caudillismo político y el neocorporativismo, al tiempo que permitirá su fácil manipulación por individuos enriquecidos al tiempo que será de uso improbable por los sectores menos favorecidos, en especial cuando la circunscripción electoral sea extensa y muy poblada. Así, bajo una pretendida expansión de la democracia, se termina abriendo espacio para la perpetuación de élites económicas. Sin embargo, un sistema de partidos basado sobre la dificultad para inscribirlos -hoy en día, por encima de los 50.000 adherentes- también permite a las mismas élites económicas adquirir su «franquicia» partidaria, mientras que los sectores populares quedan condenados a influir en la política estatal «desde afuera». Así las cosas, parece más razonable mantener la representación política centrada en los partidos políticos, pero disminuyendo los requisitos de adherentes relacionados con su inscripción.

Entre los derechos políticos destaco el reconocimiento del derecho al sufragio en las elecciones locales (corregimiento, municipio) a los extranjeros residentes en la respectiva circunscripción, en el mismo sentido que lo pretendió la Constitución Nacional

33. No sobra decir que en nuestro entorno, a pesar de que la «libre postulación» tiene únicamente una regulación que exige acompañar las postulaciones de un número de adhesiones ciudadanas para ser aceptada por el Tribunal Electoral en los únicos supuestos autorizados (elecciones locales), suele manejarse en el discurso político como una postulación sin requisitos de esa naturaleza. 
de 1946. Se trata de dar participación a aquellos extranjeros residentes de forma permanente, obviamente en una situación migratoria normalizada, únicamente en el sufragio activo, porque son parte de la comunidad en la que viven y están igualmente preocupados por el funcionamiento de la administración del barrio o la ciudad en la que trabajan y viven de forma permanente. No se trata de extender ese derecho a quienes no tienen una estancia regularizada ni documentada apropiadamente.

\section{IX. ÓRGANO LEGISLATIVO Y ÓRGANO EJECUTIVO}

Desde mi punto de vista son numerosos los elementos contenidos en el proyecto que sirven para depurar el funcionamiento de la Asamblea Legislativa. Por un lado, fortalecerla en sus competencias tradicionales y, en especial, en su labor de control de la Administración. Destaco entre éstas la aclaración sobre los efectos del voto de censura a los ministros de Estado, que incluiría su remoción, la regulación del deslinde sobre la Cuenta General del Tesoro (la ejecución presupuestaria), la aclaración sobre la obligación de comparecer a la Asamblea a las autoridades e individuos que ésta convoque (sobreponiéndose a interpretaciones jurisdiccionales de los últimos años en los que se escudan funcionarios para no rendir cuenta de sus actos ante los representantes populares); aprobar la designación de embajadores; aprobar los empréstitos que pretenda suscribir el Ejecutivo por encima de cinco millones de dólares). Igualmente se aclara el procedimiento para objetar proyectos de ley, en un sentido que lo hace menos dependiente del capricho de los presidentes.

Probablemente, el único instrumento aislado del control político del Ejecutivo por el Legislativo que consideramos relevante y que no queda recogido en el proyecto de la Asamblea Legislativa, es el voto de censura del presidente de la República, tal y como queda consagrado en el proyecto del ILDEA. Ciertamente, el tema de la responsabilidad política de un presidente en los regímenes presidenciales, siempre se ha establecido directamente con su electorado y constituye uno de los rasgos esenciales para distinguir un régimen presidencial de uno parlamentario. Si bien valoramos la adopción o adaptación de instituciones parlamentarias que mejoren el control político en el marco de nuestro régimen presidencial, el mejor ejemplo de los cuales es el voto de censura a los ministros de Estado. Éste se ejercería sobre funcionarios no electos y su utilización no desnaturalizaría el régimen político en su conjunto. No se trata, por supuesto, de negar la posibilidad de reemplazar el régimen presidencial y adoptar un régimen parlamentario, pero debo reconocer que el proyecto de la Asamblea Legislativa explota las posibilidades del régimen presidencial y no se propuso, en ningún momento, atravesar esa frontera.

Otro rasgo interesante del proyecto de ILDEA es la reducción de los recesos legislativos de los cuatro meses actuales (divididos en dos recesos de dos meses cada uno) a un único receso de un mes (que tiene unas obvias reminiscencias vacacionales). Esto podría tener el efecto de aumentar la productividad legislativa, al tiempo que reduce la injerencia del Ejecutivo por vía de la convocatoria a sesiones extraordinarias. Para 
atender el problema de la productividad, el proyecto de la Asamblea opta por el establecimiento de las comisiones legislativas plenas que, integradas proporcionalmente por las fuerzas representadas en la Asamblea, podrían dar trámite expedito a iniciativas legislativas que no sean expresamente excluidas de esa posibilidad. Por ejemplo, quedarían expresamente excluidas las leyes en materia electoral, el establecimiento de sanciones penales, la creación de impuestos, entre otros temas. Es un diseño tomado de la experiencia constitucional de Costa Rica donde ha tenido notable éxito. No estaría mal tampoco, plantearse la reintroducción de la comisión legislativa permanente para legislar durante los recesos y realizar una permanente fiscalización del Ejecutivo (y no limitarla a ocho meses al año), al tiempo que se endereza la jurisprudencia constitucional actual sobre el carácter facultativo de las sesiones de comisión realizadas durante los recesos.

Por otro lado, los aspectos que se han cuestionado sobre el diseño del órgano ejecutivo y que pueden reconocerse fácilmente, corresponden: en primer lugar, a la integración del ex presidente como legislador y a que la reelección presidencial se prohíbe únicamente durante el período inmediatamente siguiente. Estos dos rasgos, en conjunto, permiten la extensión de la relevancia política de los ex presidentes, de una forma que muchos no han creído oportuna. Ciertamente, como cambios, no contribuyen en nada esencial: la relevancia política de los ex presidentes, sobre lo que hemos tenido experiencias recientes y actuales de gran envergadura, no tiene necesidad de ser respaldada con estos mecanismos institucionales. Dicho esto, la limitación a la posibilidad de la reelección se entiende sobre todo respecto del período inmediato, por aquello de la preocupación por el uso que pueda hacerse de la posición y de los recursos oficiales, pero no puede justificarse así durante dos períodos.

Otros aspectos que no se han mencionado, quizá porque no se introdujeron modificaciones al régimen vigente, deben ser atendidos: tal es el caso del régimen de permisos y licencias del presidente de la República, que puede ser mejorado.

En lo referente a la inmunidad parlamentaria, hay notables restricciones. No se extiende a la «persecución» judicial de los legisladores, sino a la privación de la libertad y a su juzgamiento. La utilización actual de la frase «no podrá ser perseguido» permitía impedir la investigación de las causas penales contra ellos. En la propuesta actual esa autorización para investigar la proporciona la Corte Suprema de Justicia, con lo que se hallaba el camino para las mismas, moderando sin embargo la posibilidad de una utilización política de las investigaciones penales. Se prohíbe toda inmunidad civil. Hasta ahora no se le han podido aplicar medidas cautelares al patrimonio del legislador, para garantizar obligaciones particulares que contrajeron y sobre las que se debate judicialmente si las ha honrado o no. Se dispone la no prescripción de las causas penales relativas a los legisladores, aunque la Asamblea haya decidido no levantar la inmunidad para juzgar. Eso garantiza que a la pérdida de la condición de legislador, la justicia pueda hacerse eficaz.

En lo relativo a las incompatibilidades, se prohíbe a los legisladores no solamente la aceptación de empleos públicos durante su mandato, sino la recepción de remuneración de cualquier tipo, de origen privado o público; no ejercerán profesiones, ni obtendrán licencias para ello. Esto ataca prácticas muy frecuentes que debilitan la 
transparencia de la actividad legislativa de los parlamentarios. Otra práctica, la recepción de diversas modalidades de remuneración y la compensación mediante viáticos y dietas, que hace igualmente opaco el conocimiento exacto de los montos pagados por el Estado a los legisladores como retribución por sus servicios, se pretende resolver con el pago único y la declaración de ilegalidad de todo otro pago.

En lo que respecta a la inviolabilidad, estimamos que ésta no debe modificarse. A pesar de las propuestas descabelladas de hacer a los representantes populares responsables de sus votos y expresiones, debo señalar enfáticamente que esto pondría fin a la función de expresión y representación popular de los parlamentarios. La única posibilidad de reforma sería la que pretendiera circunscribir la inviolabilidad a temas (de interés público) o lugares (dentro del debate parlamentario, en el Palacio Justo Arosemena, en eventos públicos). Sin embargo, la necesidad de una autoridad que determine qué expresión es o no de interés público y la ubicuidad de los problemas que atienden los legisladores, parece poco recomendable adoptar esas alternativas.

La integración de la Asamblea es otro de esos asuntos espinosos. Los rasgos más llamativos de la Asamblea en el proyecto que estamos reseñando son: el mantenimiento de su nombre (algo relativamente impropio, pues sus funciones son más que legislativas, así que sería mejor denominarla Asamblea Nacional) y el límite de 75 legisladores que se estableció sobre el esquema de que la actual Asamblea Legislativa elegirá el próximo mayo a 78 parlamentarios. Así, la modificación en el número, que aplicaría según las disposiciones finales del proyecto únicamente a partir de las elecciones de 2009, con un aumento temporal por la elección a mitad de ese mandato de un grupo de legisladores en circunscripción nacional.

La combinación de legisladores provinciales (Bocas del Toro y Darién, excluyendo las comarcas), legisladores comarcales (Kuna Yala, Mandungandí, Wargandí, Ngobe Buglé, Emberá Wounnan), legisladores circuitales (incluyendo el circuito especial metropolitano) y legisladores nacionales (elegidos a mitad de cada mandato presidencial); responde a satisfacer las distintas necesidades de representación, y es suficientemente diverso como para no poder establecer de antemano y con certeza, los resultados que su implantación podría conllevar.

\section{Administración de Justicia}

En el tratamiento de los derechos fundamentales, con incidencia en los procesos penales y constitucionales, ya hay un impacto notable en la Administración de Justicia. Sin embargo, no son las únicas novedades, pues deben incluirse las relacionadas con el establecimiento del Consejo General del Poder Judicial para administrar la organización judicial; el cambio en el proceso de selección de los magistrados de la Corte Suprema de Justicia; la eliminación de la figura de los suplentes de magistrados (medida que pretende contribuir a la transparencia en las decisiones y a su idoneidad profesional); la introducción de una Sala Social para tratar los temas de casación laboral y otros actualmente asignados a la Sala de lo Contencioso Administrativo, entre otros. 
SALVADOR SÁNCHEZ GONZÁLEZ

HACIENDO CONSTITUCIONES DEMOCRÁTICAS. EL PROYECTO DE CONSTITUCIÓN DEL

CENTENARIO PREPARADO POR LA ASAMBLEA LEGISLATIVA DE LA R. DE PANAMÁ

También se expande la labor del instituto de defensoría pública y se hace obligatorio para alcanzar el grado de abogado del servicio público en el Estado, a la manera de los médicos, con lo cual se puede obtener asesoría legal sobre todo a nivel de los gobiernos locales.

La idea de incorporar a los Corregidores a la Administración de Justicia, bajo la denominación de «Jueces Corregidores», con las garantías de formación profesional y revisión por superiores judiciales, fue desarrollada sobre una fórmula promovida por el ex magistrado Edgardo Molino Mola.

\section{AdMinistración teRRITORIAL DEL EstADO}

Lo más importante, en lo relativo a la administración territorial del Estado, es la confirmación de las Comarcas como entes territoriales autónomos que, sin embargo, engarzan mejor con la Constitución, al constitucionalizar mecanismos de participación democrática de sus habitantes. Por un lado, la necesidad de que se expresen sus organismos por medio de instrumentos jurídicos, revisables por las autoridades judiciales y la administración de recursos estatales fiscalizables por los medios tradicionales de control del Estado, incluyendo, en primer lugar, la incorporación de presupuestos específicos dentro del Presupuesto General del Estado. Aunque no se perciba con claridad, hoy en día existe una falta de institucionalización del hecho jurídico conocido como «comarca», lo que involucra una penosa dispersión de los recursos económicos y humanos dedicados a atender sus necesidades, una falta de claridad sobre los regímenes jurídicos aplicables y falta de garantías respecto al proceso político (incluyendo las elecciones para integrar los estamentos tradicionales) como respecto a los derechos fundamentales de los panameños indígenas y no indígenas. Así las cosas, creemos firmemente que éste es el camino idóneo para enmendar la fórmula política actual y dotarle no sólo de un mejor presente, sino de un futuro más adecuado.

El otro aspecto importante de la propuesta sobre el régimen territorial es la opción de establecer un distrito especial en el área de la ciudad de Panamá. Si bien es una idea interesante y en gran medida necesaria, al parecer puede confrontar problemas en relación con las responsabilidades políticas actualmente distribuidas entre el Distrito de San Miguelito y el Distrito de Panamá. Sin embargo, ése es precisamente el problema: la solución de los problemas urbanos en la capital sólo puede hacerse a través de un alto nivel de coordinación, que por un lado implique el abandono de competencias por parte del gobierno central a favor de las autoridades locales, por otra el traslado de recursos para ejecutar las tareas necesarias, y por último, la articulación de los dispersos gobiernos locales que actualmente malviven en un área densamente poblada.

Con carácter general, esta forma de entender el problema deriva en el reconocimiento de la posibilidad de trasladar competencias desde el gobierno central hacia los gobiernos locales, que no se hace obligatorio sino posible (artículo 322 del proyecto de la Asamblea Legislativa), previa una negociación coordinada desde el Ministerio de Gobierno (actual responsable de la coordinación con los gobiernos locales). 


\section{REFORMA DE LA CONSTITUCIÓN}

Un último aspecto relevante es la adopción del mecanismo de reforma conocido como Constituyente Paralela. En el pasado reciente ya se propuso varias veces, la más reciente y políticamente relevante, en uno de los Actos Legislativos aprobados al final del mandato de Guillermo Endara en 1994; que, sin embargo, no fue adoptado al principio del mandato de Ernesto Pérez Balladares, como se requería para adquirir vigencia.

Entre las características que resaltan de la propuesta de la Asamblea, están la posibilidad de la iniciativa popular de reforma constitucional y la posibilidad expresa de control de la constitucionalidad sobre el procedimiento empleado en la aprobación de una reforma constitucional.

Vale la pena reiterar, como he dicho al principio de este capítulo, que incluso en nuestro pasado colombiano, las constituciones que adoptaba Panamá solían prever la vía de reforma mediante constituyentes constitucionalizadas.

\section{HACER CONSTITUCIONES DEMOCRÁTICAS}

Un precepto aceptado del constitucionalismo señala que una sociedad no tiene Constitución, si no está asegurada la garantía de los derechos ni determinada la separación de los poderes ${ }^{34}$. Hoy sabemos que en una democracia estos dos rasgos adquieren toda su potencialidad, pero en el origen del constitucionalismo la universal participación popular no se veía como parte de la ecuación: ya era un gran avance encontrar límites al poder público en los derechos de las personas y en su distribución entre autoridades diversas.

Para nosotros, sin embargo, lo importante es hacer constituciones democráticas, en las que los logros del constitucionalismo de primera época se preserven, pero en las que se garantice la participación de los ciudadanos a todo nivel en la toma de decisiones públicas, así como la red de instituciones sociales que dan realización material a la libertad que se pregona. Desde esa perspectiva, el proyecto de Reforma Integral de la Constitución, preparado en la Asamblea Legislativa, es un proyecto profundamente democrático.

También es importante la forma en que esas constituciones se aprueban, aunque hoy es común indicar, con carácter general, que si la Constitución no es hecha por sus propios destinatarios o a través de sus agentes, no es Constitución, sino una Carta Fundamental otorgada, que puede o no ser democrática en sus disposiciones, pero que se encontrará deslegitimada por no ser el producto de un proceso democrático. Los proyectos de Constitución no tienen que ser preparados en procesos democráticos, porque lo fundamental del proceso democrático no es el origen de los borradores o las referencias, sino el debate público y abierto de quienes cumplen la labor de decisión

\section{Artículo 16 de la Declaración Francesa de los Derechos del Hombre y del Ciudadano.}


constituyente y la relación, mucha o poca, con los individuos que integran ese sujeto político que entendemos titular original del poder público. Sin embargo, los proyectos enriquecidos por la variada opinión de los ciudadanos siempre podrán aparecer como de mayor utilidad a los procesos concretos de cambio constitucional, que aquellos herméticos a los aportes de los distintos sectores que integran la sociedad. El caso del proyecto de la Asamblea Legislativa es indudablemente de aquellos en los que la impronta de la consulta tiene una huella más clara.

La acumulación de propuestas de reforma constitucional -la del IDEN, la del ILDEA, la de APEDE, la del Foro Visión 2020 y la de la Asamblea Legislativa- nos permite concluir que la primera tarea de las dos que mencionábamos al inicio de este escrito, la de ofrecer textos constitucionales alternativos a los vigentes, está cumplida ampliamente. Así, va llegando el momento de ejecutar un plan de acción.

Ya en las primeras páginas de este artículo señalaba que el mecanismo de adopción de una nueva Constitución era y es objeto de debate, en la doctrina y en la cotidianidad política de la República de Panamá. Si toda reforma, según los métodos constitucionalizados, debe ser discutida y aprobada por la Asamblea Legislativa (en solitario, según uno de los métodos; con intervención directa de los electores a través de referéndum, en el otro), no podemos negar su fundamento democrático: la Asamblea está integrada por legisladores elegidos popularmente. En abstracto, una Asamblea Constituyente no podría ser más democrática que una Asamblea Legislativa, en el sentido de estar integrada por representantes populares electos por los ciudadanos. En concreto, sin embargo, es posible imaginar la integración de una Asamblea Constituyente por parámetros más amplios que los actualmente aplicados a la integración de la Asamblea Legislativa. Así, es posible entender que un plan de acción alternativo a la utilización de los métodos de reforma constitucionalizados, pueda imaginarse más democrático en la práctica. Un ejemplo de esto es la idea de que el monopolio partidario de la representación política en la Asamblea Legislativa hace, por sí solo, a una Asamblea Constituyente un foro más democrático para discutir y aprobar un nuevo texto constitucional, si la convocatoria de la Asamblea Constituyente no reproduce ese esquema del monopolio partidario.

No menos importante es la gestación de la decisión de convocar una Asamblea Constituyente y las formas jurídicas que esa convocatoria adoptaría, con la evidente pretensión de sobrevivir a la impugnación jurídica y política de la que seguramente sería objeto. Ese sujeto denominado pueblo, que identificamos como titular del poder constituyente, puede expresarse de formas diversas según se le formule una consulta.

En este punto, lo mejor será cotejar esa propuesta del Centro de Iniciativas Democráticas, en la que participé junto a Jorge Giannareas y Alfredo Castillero, que se refería inicialmente al marco jurídico legal de la convocatoria a un referéndum para consultar a los ciudadanos sobre su voluntad de convocar o no a una Asamblea Constituyente. Esa propuesta fue presentada a diversos actores sociales, incluida la Asamblea Legislativa y el Foro Visión 2020 durante 2003. Ante la dificultad de obtener una decisión favorable en las asambleas del Foro (por el veto de los partidos políticos que en él participan), la tesis ha terminado siendo acogida recientemente por el 
Comité Ecuménico Nacional, en la forma de un primer paso de consulta «informal» en los templos cristianos del país, a través de la recogida de firmas, desde el 19 de octubre de 2003 y por dos meses consecutivos. La consulta «formal» a través de un referéndum que tendría lugar simultáneamente a las elecciones generales de mayo de 2004, es todavía una incógnita. También es una incógnita, la formulación jurídica que lo permitiría.

Poco después de la presentación pública de la versión definitiva del proyecto de la Asamblea Legislativa, que parecía la conclusión de su ciclo vital, despuntó la candidatura presidencial de Guillermo Endara, uno de cuyos pilares es la convocatoria de una Asamblea Constituyente para cambiar la Constitución al margen de los mecanismos de reforma establecidos ${ }^{35}$. Súbitamente, algunos de los que habían desestimado la oportunidad de la reforma promovida desde la Asamblea, redescubrieron su utilidad al enfrentar una creciente amenaza electoral al predominio de las principales fuerzas políticas. Una amenaza que era alimentada por unas exigencias populares que no habían sido oportunamente atendidas por los partidos mayoritarios, al aprobar que el caso CEMIS fuera cerrado sin la determinación judicial de los responsables y la correspondiente adjudicación de sanciones.

Sin perjuicio de que otras alternativas se ofrezcan en el futuro próximo, el examen de la situación al momento de escribir estas líneas permite cotejar la convocatoria de una Asamblea Constituyente con los parámetros usuales de lo que entendemos que es democrático o no. Si nos percatamos de sus notas características, definitivamente lo es. Desde mi perspectiva, la consulta popular sobre la convocatoria de una Asamblea Nacional Constituyente, no es otra cosa que la culminación de los esfuerzos por dotar de una expresión práctica a la general convicción sobre su necesidad. El futuro señalará si esos esfuerzos darán frutos.

\section{BiBLIOGRAFÍA}

ACKERMAN, Bruce. El futuro de la Revolución Liberal. Barcelona: Ariel, 1995.

AleXY, Robert. Teoría de los Derechos Fundamentales. $1^{a}$ edición. Madrid: Centro de Estudios Constitucionales, 1993.

AraúZ, Heriberto. Hacia una Nueva Constitución Política. Universal Books, 2003.

De VegA, Pedro. La Reforma Constitucional y la Problemática del Poder Constituyente. $1^{a}$ edición. Madrid: Editorial Tecnos, 1985.

Garrorena Morales, Ángel. El Estado Español como Estado Social y Democrático de Derecho. Madrid: Editorial Tecnos, 1987.

35. Un despunte en gran medida provocado por dos eventos relacionados: la aprobación legislativa de la Resolución n. ${ }^{\circ} 39$ del 30 de junio de 2003, que negó el solicitado levantamiento de la inmunidad parlamentaria de los legisladores en razón del caso CEMIS, rechazó igualmente las renuncias a la inmunidad presentadas por algunos legisladores y declaró sin efecto lo actuado por el Ministerio Público, por un lado, y el fallo de la Corte Suprema de Justicia de 17 de septiembre de 2003 que declara la nulidad de todo el proceso penal contra los legisladores y declara la nulidad de todo el proceso. 
SALVADOR SÁNCHEZ GONZÁLEZ

HACIENDO CONSTITUCIONES DEMOCRÁTICAS. EL PROYECTO DE CONSTITUCIÓN DEL

CENTENARIO PREPARADO POR LA ASAMBLEA LEGISLATIVA DE LA R. DE PANAMÁ

GonzÁlez MARCos, Miguel. En Nombre de la Democracia. Optar entre un Tribunal Constitucional y una Sala Constitucional en el Ordenamiento Jurídico Panameño. Panamá: Editora Libertaria (EDILIBER), 2003.

GonzÁlez Montenegro, Rigoberto. Estado Constitucional y Mecanismos de Defensa Constitucional. Panamá: Instituto de Estudios Políticos e Internacionales, 1997.

GonZÁlez, José M. y QuesadA, Fernando (eds.). Teorías de la Democracia. Barcelona: Anthropos, 1988.

Hamilton, Alexander et al. El Federalista. México: Fondo de Cultura Económica, 1994.

Отто, Ignacio de. Derecho Constitucional. $2^{a}$ edición. Barcelona: Ariel, 1995.

Pemán Gavín, Juan. Las Leyes Orgánicas: Concepto y Posición en el Sistema de Fuentes del Derecho. En Estudios sobre la Constitución Española. Madrid: Civitas, 1991.

QUiNTERO CORREA, César. Crítica a la Teoría Tradicional del Poder Constituyente. Panamá: Editorial Portobelo, s/f.

SÁnCHEZ GonzÁlez, Salvador. Transición a la Democracia en Panamá y el Ocaso de los Militares. En García La Guardia, Jorge Mario et al. Transición Democrática y Reforma Constitucional en Centroamérica. Fundación del Servicio Exterior para la Paz y la Democracia, pp. 177-190.

- Reforma Constitucional o Nueva Constitución. Conferencia ofrecida durante el Congreso Nacional de Abogados, 6 de agosto de 2002.

RiCORD, Humberto. La Constitución de 1983. En FÁBREGA P., Jorge (ed.). Ensayos sobre Historia Constitucional de Panamá. $2^{a}$ edición. Panamá: Editora Jurídica Panameña, 1991, pp. 753 768.

ReQueJO PAGÉs, Juan Luis. Las normas preconstitucionales y el mito del poder constituyente. Madrid: Centro de Estudios Constitucionales, 1998.

SchmitT, Carl. Teoría de la Constitución. Madrid: Alianza, 1982.

- La Defensa de la Constitución. Madrid: Editorial Tecnos, 1983.

\section{OTROS DOCUMENTOS}

Propuesta de Constitución Política del Centenario. Asamblea Legislativa de la República de Panamá, agosto de 2003.

Anteproyecto de Constitución Política Para la República de Panamá. Instituto de Estudios Nacionales de la Universidad de Panamá, enero de 1994.

Proyecto de Nueva Constitución. Instituto Latinoamericano de Estudios Avanzados. Panamá, 1993.

Proyecto de Nueva Constitución. Asociación Panameña de Ejecutivos de Empresa, Panamá, agosto de 2003.

Propuestas de la Mesa Nueva Constitución del Foro Visión 2020, agosto de 2003.

Constitución NaCional de la República Argentina.

CONSTITUCIÓN DE LA FEDERACIÓN SUIZA.

Constitución Política de la República de Panamá.

Declaración Francesa de los Derechos del Hombre y el Ciudadano. 